This is a penultimate draft of a paper to appear in Journal of the History of Biology (Springer). Please refer to the published version:

http://link.springer.com/article/10.1007/s10739-016-9451-x

\title{
Building a science of animal minds: Lloyd Morgan, experimentation, and Morgan's Canon
}

\author{
Simon Fitzpatrick
}

Department of Philosophy

John Carroll University

sfitzpatrick@jcu.edu

\section{Grant Goodrich}

The Krause Center for Leadership and Ethics

The Citadel

ggoodric@,citadel.edu

\section{Introduction}

Textbook histories of psychology and animal behaviour research usually identify the British philosopher-psychologist, Conwy Lloyd Morgan (1852-1936), as the father of modern comparative psychology. The standard narrative has it that, in the last few decades of the nineteenth century, comparative studies of animal intelligence had attained great significance in the wake of Charles Darwin's theory of evolution, which was seen as predicting "psychological, no less than a physiological continuity extending throughout the length and breadth of the animal kingdom" (Romanes, 1882a, p10). Darwin (1871) and, most notably, his protégé, George Romanes (1882a, 1883a), sought to document the nature and extent of this psychological continuity between humans and animals. Morgan, however, criticized the methods employed by Romanes and others, particularly their reliance on informal, anecdotal reports of animal intelligence, and was deeply sceptical about the sweeping and seemingly romantic claims they had made about the impressive psychological capacities of animals. Morgan's work, in particular his $A n$ Introduction to Comparative Psychology (1894c), constituted a bold manifesto for a more rigorous science of comparative psychology, which ultimately laid the foundations for the experimental approaches to comparative psychology that emerged in the early decades of the twentieth century. ${ }^{1}$

\footnotetext{
${ }^{1}$ In particular, Morgan's work has been seen as providing direct inspiration for Thorndike's (1898) experimental studies of animal learning, and thus as an important stimulus for the behaviourist movement. As result, Morgan has often been regarded as a proto-behaviourist. However, as numerous Morgan scholars have shown (see, e.g., Costall, 1993; Wozniak, 1993; Thomas, 1998), and as will become apparent from
} 
Central to Morgan's scientific reformation of comparative psychology was a methodological principle now known as "Morgan's Canon":

In no case may we interpret an action as the outcome of the exercise of a higher psychical faculty, if it can be interpreted as the outcome of the exercise of one which stands lower in the psychological scale. (Morgan, 1894c, p53).

This principle, intended as a guideline for the interpretation of animal behaviour, went on to play an enormously influential role in the subsequent history of comparative psychology, and continues to play a significant role in modern debates about the nature of animal minds (Radick, 2007; Fitzpatrick, 2008)—so much so that it has been referred to as "[p]erhaps, the most quoted statement in the history of comparative psychology" (Dewsbury, 1984, p187). Honouring the dictates of Morgan's Canon is still widely believed to be a fundamental prerequisite for scientific rigour when investigating the minds of animals.

Morgan's attitude towards comparative psychology and its scientific status had, however, undergone significant evolution by the time of the writing of the Introduction. In a series of papers published in the early-to-mid 1880s, Morgan (1882, 1884a, 1884b, 1886) expressed a deep scepticism about the very possibility of a genuine science of the internal psychological workings of animals. The most that was possible, he argued, was "the scientific study of the [external] habits and activities of animals" (Morgan, 1886, p180). Yet, by the time of the Introduction, he had become very much a proponent of a science of animal minds, and was busy trying to articulate a vision for how it should be practiced.

There has been a fair amount of disagreement amongst scholars of Morgan's work about the nature, timing, and causes of this shift in Morgan's thinking. For instance, Boakes (1984) suggests that Morgan became more optimistic about the prospects for a genuine science of animal mentality as a result of the experiments he conducted circa 1891-1894 on the behavioural development of young chicks and ducklings (Morgan, $1892 \mathrm{~b}, 1893,1894 \mathrm{a}, 1894 \mathrm{~b})$, the results of which ran contrary to some of his earlier

our discussion, though Morgan's early views did have somewhat of a proto-behaviourist flavour to them, his mature vision for comparative psychology was severely at odds with the approach later advocated by the behaviourists. 
pronouncements in Animal Life and Intelligence (1890-1). This experience supposedly prompted Morgan towards the view that, in contrast to the informal, anecdotal approach adopted by Romanes, questions about the psychological causes of animal behaviour could in fact be satisfactorily answered through controlled experimental methods (see also Goodrich and Allen, 2007). Richards (1987), however, sees the chick experiments as supplementing a pre-existing impetus towards greater optimism generated by Morgan's evolving monistic view of the relationship between mind and body. According to Richards, Morgan's initial doubts about the possibility of comparative psychology was a residue of his early fascination with Bishop Berkeley's idealism, which precipitated a sceptical epistemological stance towards the problem of inferring mental states in nonhuman animals. However, in the course of their exchanges during the mid-1880s, Romanes managed to convince Morgan that if the dual-aspect monism to which they were both inclined was true, a window into the animal mind could be found by uncovering homologous "neuroses" (neurophysiological processes) in the brains of animals and man, which would then be indicative of homologous "psychoses" (mental processes). According to Costall (1993), however, Boakes and Richards fail to appreciate the extent of the rapprochement with Romanes. In particular, Boakes and Richards both see Morgan's Canon as functioning as a prophylactic against the anthropomorphism of Romanes. Costall says of Morgan's Introduction that it was “clearly not a 'revolt' against Romanes' anthropomorphism, but rather a concession to Romanes' insistence upon the necessity of an anthropomorphic approach to the study of animal psychology" (1993, p120). For Costall, then, Morgan eventually ended up aligning himself almost completely with the ideas and methods of Romanesian comparative psychology; the Canon was simply a tool to make the Romanesian approach more rigorous.

Despite these disagreements, Boakes, Richards, and Costall view Morgan's Canon as more or less an inevitable consequence of comparative psychology becoming a more professionalized and methodologically self-conscious discipline. Radick (2000, 2007), however, has presented a quite different take on the specific origins of Morgan's Canon. For Radick, Morgan's Canon was actually a codification of Morgan's adherence to the Lockean doctrine that language was a necessary prerequisite for higher cognition. In addition, in particular contrast to Costall and Richards, Radick sees Morgan as a 
consistent sceptic throughout the 1880 s, but one who became rather more optimistic about the possibility of a science of animal minds due to his reading of William James around 1890-1891. James convinced him that what he and Romanes (following W.K. Clifford) had called the "ejective" method in comparative psychology - the method that both regarded as fundamental to inferences to mental states in other creatures - could be practiced in a rigorous manner.

While we believe that these scholars have made important contributions to our understanding of Morgan's intellectual development, none of these narratives is fully adequate. Our goal in this paper is to provide a more complete picture of this important episode in the history of comparative psychology. We will argue that Morgan actually underwent two quite different shifts of attitude towards the proper practice of comparative psychology. The first, which culminated in Morgan's Animal Life and Intelligence (1890-1), involved a move towards a qualified acceptance of Romanes' approach to comparative psychology. The second, which began not long after the publication of Animal Life and Intelligence, culminating with the Introduction of 1894, was a shift away from Romanes' reliance on systematizing the available mostly anecdotal evidence towards a thorough-going experimental approach to the investigation of animal cognition, focused in particular on studying the development of behaviour. Building on the account provided by Richards, we will emphasize the role of Morgan's evolving epistemological views in bringing about the first shift. In particular, we will highlight an aspect of Morgan's work that has attracted very little previous attention: his philosophy of science. When it comes to understanding the second shift, we will emphasize the role of an intriguing but largely overlooked figure in the history of comparative psychology, T. Mann Jones, whose correspondence with Morgan provided an important catalyst for Morgan's experimental turn, and substantially influenced the developmental focus of the experimental approach that Morgan ultimately endorsed.

In telling this story, we also want to shed light on the intended function of Morgan's Canon, the methodological principle for which Morgan is now mostly known. It is our contention that the Canon can only be properly understood by seeing it in the context of Morgan's own unique experimental vision for comparative psychology. 


\section{Morgan's early scepticism about comparative psychology}

Morgan's early views about the scope and limits of comparative psychology were boldly expressed in a series of articles published in the early-to-mid 1880s. ${ }^{2}$ The most striking and programmatic of these was an article published in Mind in 1886, called "On the study of animal intelligence", which expanded on arguments made in his 1885 book, The Springs of Conduct. ${ }^{3}$

Morgan began by discussing the sorts of reports of animal intelligence that Romanes had collected together in his 1882 book, Animal Intelligence. Romanes had described the volume as a compendium of "facts" of animal intelligence, which could then be used by researchers to work out the details of how psychology had evolved throughout the animal kingdom - something that he tried to do in the follow-up volume, Mental Evolution in Animals (1883a). The book presented a wide-ranging survey of what Romanes took to be the existing evidence for intelligence in a large variety of animal species, from amoeba and molluscs, to elephants and great apes. Like the evidence reported by Darwin in The Descent of Man, the "facts" collected in Animal Intelligence consisted, for the most part, in anecdotal reports of animal behaviour: recollections of chance observations of interesting behaviour communicated to him by correspondents, reported in the scientific literature, or recorded by Romanes himself.

Though Romanes had, by his own account, tried to make the "phenomena of mind in animals, having constituted so much and so long the theme of unscientific authors... a worthy object of scientific endeavour" (Romanes, 1882a, pVI), Morgan saw serious problems in the way that Romanes and his correspondents discussed these interesting instances of animal behaviour. The main problem, according to Morgan, was disentangling the "facts" from the "inferences" in the reports. Alongside providing factual descriptions of the actions of animals in particular circumstances, the witness normally also, usually unintentionally, described the situation in such a way that made substantive, but undefended, assumptions about the underlying psychology of the animal involved. As an example, Morgan discussed a report cited by Romanes of an orangutan

\footnotetext{
${ }^{2}$ For biographical details on Morgan, see Morgan (1930), Richards (1987), and Radick (2007).

${ }^{3}$ In a manner not uncommon for philosopher-scientists of the time, Springs of Conduct was a work of staggeringly wide scope, featuring discussions of topics ranging from zoology, chemistry, psychology, metaphysics, and philosophy of science. The latter was a recurrent theme throughout the book, and is, as we will argue, vital to understanding Morgan's early scepticism about comparative psychology.
} 
who untied three knots on a rope that was otherwise too short to be used to reach a key. Alongside describing the fact of the orang untying the knots, the witness also described the situation as one where the animal recognized "the nature of the obstacle to his desires" (Morgan, 1886, p174). This, Morgan claimed, was not an observational fact but an inference, and, moreover, one that might not have been made by another witness to the same event. Thus, a problem with this kind of anecdotal "evidence" of animal intelligence was that the report itself often begged the question about the type of psychological process involved. This was clearly not the way to do good science- the facts of the case had to be clearly separated from the inferences being made by the witness, and differential evidence was needed for making those particular inferences rather than others also consistent with the facts.

But, even when we were clear about what was being observed and what was being inferred in these reports, there remained, Morgan argued, a deep epistemological problem for comparative psychology. Morgan agreed with Romanes that if a science of the minds of other creatures was possible, the primary method of inquiry was what W.K. Clifford $(1874,1878)$ had called "ejective". Theorizing about the nature of minds other than our own was done, first, by introspecting on the causes of our own behaviour under various circumstances, so as to reach an understanding of the range of mental processes operative in our own minds, and then reasoning by analogy to infer possible causes of similar behaviour in the other creature in question. The key problem, for Morgan, was how to verify such "ejective" inferences. Experience showed that introspection on one's own psychological workings was often a less than reliable guide to the minds of other human beings, especially people from different cultures. Yet, at least with humans, we had the possibility of using linguistic communication to check the accuracy of our ejective inferences. Thus, "[1]anguage makes possible the social eject; and thus makes possible a science of Human (as opposed to Individual) Psychology" (1886, p176). ${ }^{4}$ Clearly, however, this tool was not available when we looked at animals. That, alongside the fact that the ejective method could lead different individuals to quite different psychological

\footnotetext{
${ }^{4}$ However, even here Morgan argued that there were limits on how much one could know about humans living in very different cultures, or even just humans with different class, economic, religious, and educational backgrounds to one's own. Scientific psychology should strictly be seen as holding good "for civilised, but not of necessity for uncivilised, folk. It is a psychology of sages, but not of savages" (1886, p176).
} 
explanations for the same observed behaviour, imposed fundamental limitations on our ability to acquire knowledge about the internal psychological workings of animals, and since we knew that the reliability of the ejective method must "hold good in diminishing degree for minds of successively lower development", our inferences concerning the "motives, minds, and characters" of animals were "so largely liable to error as to render the drawing of them unprofitable for purposes of scientific investigation" (1886, p177).

The early Morgan did not deny that we could be sure that animals had minds. He accepted that since they had "inherited brain-structures in many respects similar to those possessed by man... there is no reason for supposing that in them no psychoses [changes in consciousness] run parallel, or are identical with their neuroses [changes in neurophysiology]" (1886, p178). He thus agreed with Romanes that the best evidence for animal mentality was documented neurophysiological homology, but he also agreed that the paucity of existing neurophysiological knowledge meant that it was the ejective method that had to do all the heavy lifting, at least until there were sufficient advances in neurobiology. Morgan did seem cautiously optimistic about our knowledge in this area increasing, but, given such existing limitations, ${ }^{5}$ we needed to be realistic about how much we could know about the nature of these minds, for not only was our ability to verify hypotheses about the nature of the minds of animals impaired by the lack of an independent check on the ejective method, the very fact that the primary method of inference in comparative psychology was ejective meant that the scope of our hypothesizing was also impaired, our interpretations of animal behaviour necessarily having to be framed in terms of our own psychology: "[if] we speak of memory, sympathy, affection, revenge, etc., as mental qualities possessed by animals, we must remember that each of these is stamped with the human image and superscription, and bears our own individual mark" (1886, p178). Drawing an analogy, Morgan asked:

Could we frame a science of Astronomy if the only method of procedure were to observe the stars and planets in mirrors of varying and unknown curvature? Harder still is the task of framing a science of Comparative Psychology out of our

\footnotetext{
${ }^{5}$ Though the balance changed over time, this tendency to weigh grounds for scepticism against grounds for optimism about the future is a persistent theme throughout Morgan's writings on comparative psychology, and (as a reviewer has suggested to us) perhaps helps to explain why Morgan wrote so much on questions of method and proper inference.
} 
ejective knowledge of the mental faculties of animals, liable as they are to inevitable errors of unknown amount. (1886, p179-180).

All of this meant that the ambitions of comparative psychology had to be drastically reined in: instead of aiming to elucidate the nature of the internal mental states and processes of animals, as the sort of comparative psychology envisioned by Romanes aimed to do, comparative psychologists should rather focus their attentions on "the scientific study of the habits and activities of animals" (1886, p180). By this he meant studying the behavioural propensities and dispositions of particular animals in various circumstances. This could include studying the "[t]he origin and mode of development of intelligent, that is specially adaptive actions and individual habits", "the age at which they manifest themselves; if there is any learning in the case", and "the organic mechanism, nervous and other, by means of which the habits and activities are carried" (1886, p185186). We could, Morgan argued, form a legitimate science of these objective and verifiable aspects of the behaviour of animals, but we should "place the motives (so difficult to get at even in the case of our neighbours) on one side, as at present beyond the reach of scientific treatment" (1886, p181). Moreover, while Morgan recognized the motivations of naturalists attempting to document evidence of psychological continuity between humans and animals in order to support the doctrine of mental evolution, he argued that loose speculation about "hypothetical motives and complex mental states" was "likely to hinder rather than advance the acceptance of the doctrine by all careful thinkers" (1886, p182).

This scepticism was reinforced by Morgan's worries about the practical inapplicability of Romanes' tripartite taxonomy of psychological faculties. Building on the work of other early psychologists - most notably Herbert Spencer's Principles of Psychology $(1855,1870-2)$ - Romanes argued that behaviour came in three basic kinds: reflexive, instinctive, and rational. Reflex action was understood as "non-mental neuromuscular adjustment, due to the inherited mechanism of the nervous system" (1882a, p17), and always involved "particular adaptive movements to particular stimulations" (p3-4). Examples of reflexes included the unconscious withdrawal of an organism's hand or foot from irritation - an adaptation that occurred even when the nerves connecting the limbs to the brain were severed (p2-3). Many such actions might appear to be the product 
of conscious choice, but reflexes involved no such conscious or intentional action. Instincts were also adaptations to particular stimuli, but what distinguished them from reflexes was the active role of the mind. In characterizing this distinction, Romanes also drew a distinction between "sensation" and "perception". Sensations were very simple sensory detections, such as detecting heat or light, or detecting physical contact at a particular point on the body. Perceptions, on the other hand, were more complex sensory detections, that involved picking out certain features of complex sensory inputs, such as detecting the presence of a particular kind of object in a wider visual field. All perception, for Romanes, involved "inference" and therefore the presence of a "mental element". Thus, reflexes and instincts could also be distinguished in terms of their initiating stimuli: automatic behaviours stimulated by brute sensations were the product of mere reflexes, whereas behaviours stimulated by more fine-grained perceptions were the product of instincts (1883a, p159-160). ${ }^{6}$ While instinctive behaviours involved conscious action, they did not involve any kind of understanding of what was being done and why, and they resulted in behaviours that tended to be shared by all normal members of a species. In contrast, reason was the faculty "concerned in the intentional adaptation of means to ends", and implied "conscious knowledge of the relation between means employed and ends attained" (p17). "Rational" or "intelligent" behaviours (Romanes used these terms interchangeably) were those that were adaptive to unique and comparatively rare situations, and were thus displayed by individuals, but not necessarily by all the individuals in the species. Romanes thus categorized all instances of individual learning from experience of the sort that could explain differences in the behaviours of individual members of the same species as instances of reason. It was at this level that truly conceptual thought took place.

While Morgan agreed with the internal logic of Romanes' taxonomy, it was, he argued, "inapplicable in practice", since it rested on extremely subtle theoretical distinctions - such as the difference between conscious and unconscious actions-which

\footnotetext{
${ }^{6}$ In light of this role of the "mental element" in instinct, Romanes stressed that learning from experiencewhich was widely seen at the time as a crucial criterion for the presence of mind - was only a sufficient, not a necessary condition of mindedness. From the fact that "a lowly organised animal does not learn by its own individual experience, we may not therefore conclude that in performing its natural or ancestral adaptations to appropriate stimuli consciousness, or the mind-element, is wholly absent; we can only say that this element, if present, reveals no evidence of the fact" (1882a, p5). Nonetheless, learning did, Romanes argued, constitute the clearest behavioural evidence for mindedness.
} 
were not easily translatable into observable differences in behaviour. It was impossible to tell, for instance, whether or not any allegedly instinctive action was not just a reflex, since the role of consciousness could not be directly observed in the behaviour itself. Consequently, it was fruitless for psychologists to attempt to pronounce on which of the faculties in Romanes' taxonomy were possessed by animals. As part of his proposal for how comparative psychology should be practiced, Morgan thus offered new definitions of reflex and instinct in what he took to be "objective", non-psychological terms: reflex actions were "those which are of the nature of organic responses to more or less definite stimuli and which involve rather the organs of an organism than the organism as a whole", while instinctive actions were "those which are performed, through the influence of inherited habit, by the individual in common with all the members of the same more or less restricted group, in adaptation to certain oft-recurring circumstances" $(1886, \mathrm{p} 184){ }^{7}$ And instead of talking about "reason", we should talk about "intelligent" actions, which were those "performed by the individual, in virtue of his individuality, in special adaptation to special circumstances" (1886, p184). While "difficulties" "may arise in the application of these definitions" they were at least, "surmountable", whereas those surrounding Romanes “ejective” definitions were "insurmountable” (1886, p184).

Morgan's diagnosis of the epistemological problems facing Romanesian comparative psychology was not original. Indeed, almost everything that Morgan said in setting up these problems could have been quoted from the introductory chapters to Romanes' Animal Intelligence or Mental Evolution in Animals. ${ }^{8}$ But, while both men

\footnotetext{
${ }^{7}$ The reference to "inherited habit" indicates that, at this point in his career, Morgan was happy to accord a role to Lamarckian inheritance of acquired characteristics in evolution-something that he became increasingly sceptical about as time went on, and which his later experiments with young birds ultimately led him reject (Boakes, 1984).

${ }^{8}$ For instance, Romanes highlighted a particular problem for the ejective method when we considered insects and other organisms so physiologically different to humans: "The whole organisation of such a creature is so different from that of a man that it becomes questionable how far analogy drawn from the activities of the insect is a safe guide to the inferring of mental states" (1882a, p9). Nonetheless, the ejective method was, he argued, the only one available to us:
}

The mental states of an insect may be widely different from those of a man, and yet most probably the nearest conception that we can form of their true nature is that which we form by assimilating them to the pattern of the only mental states with which we are actually acquainted. And this consideration, it is needless to point out, has a special validity to the evolutionist, inasmuch as upon his theory there must be a psychological, no less than a physiological continuity extending throughout the length and breadth of the animal kingdom. (1882a, p10). 
highlighted exactly the same problems with the ejective method, they were each led to very different conclusions: while Romanes remained optimistic about the possibility of a genuine science of animal minds - as opposed to a science merely of the habits and activities of animals - the early Morgan saw these problems as imposing fundamental limits on our ability to know anything substantive about animal psychology. Indeed, Morgan's strategy in the Mind paper was in essence to show how Romanes' own views about the methods of comparative psychology led to a profound scepticism about his claims about animals intelligence.

Finally, as Radick $(2000,2007)$ has emphasized, Morgan had a theoretical reason for denying that animals have reason. Romanes had argued that cats, dogs, and numerous other species possessed the ability to entertain abstract ideas of qualities such as redness, good for eating, or bad for eating. However, in a letter to Nature in 1882, Morgan defended the Lockean doctrine, then promoted most notably by the philosopher and Sanskrit scholar F. Max Müller, that the ability to engage in "abstraction"- and with it all truly conceptual thought—-went hand-in-hand with language:

I believe [...] abstract ideas to be impossible for the brute, I believe them to be the outcome of the use of language. We see a plum, and we find that it is round, and blue, and resisting. From these words we form abstract nouns, roundness, blueness, resistance. We then proceed to manufacture a something to which each of these words may answer, and we call that something a quality. Having thus made the quality, the next thing we do is to try and endow it with a separate existence, and to the results of our endeavours we give the name abstract idea. All this process which grows out of our use of words under the influence of a developed power of reflection... Without a considerably developed use of symbols such a process is impossible. Hence I believe that no animal can form an abstract idea... (Morgan, 1882, p524).

Thus, not only did the methods of comparative psychology fail to provide a secure basis for inferring anything very interesting about the psychological capacities of animals, we also had strong theoretical reasons for believing that animals lacked sophisticated forms of cognition-specifically, the kinds of abstract conceptual thought distinctive of what Romanes and others called "reason".

Note the role that the theory of evolution, and the psychological continuity it seems to imply, plays in justifying the use of the ejective method. 


\section{From sceptic to proponent}

Morgan's criticisms of Romanes led to a number of exchanges between the two men. Romanes (1884) offered what he regarded as a reductio of Morgan's arguments: they ultimately led to the impossibility of a science of the human mind as well as one of the animal mind. In particular, Romanes saw no reason to assume that linguistic communication was in fact a reliable check on the ejective method. Hence, since a science of the human mind using the ejective method was clearly possible, so was a science of the animal mind.

However, much had changed in Morgan's attitude towards comparative psychology by the time Animal Life and Intelligence appeared in 1890-1. In this work, though Morgan often found places to object to Romanes, his tone was one of praise as much as criticism. For example, he spoke of Romanes' "careful and exact observations, his patient and thoughtful inferences, and his lucid and often luminous exposition" (18901, p433-434). Most tellingly, however, Morgan's use of the terms "reflex", "instinct", and "intelligence" was now much closer to Romanes' definitions than to his earlier, purely behavioural characterizations.

In Morgan's 1886 Mind paper, Romanes was criticized for his references to consciousness in the definitions of "instinct" and "intelligence", on the grounds that specific attributions of consciousness to animals could not be objectively verified. According to Morgan's 1890-1 taxonomy of psychological faculties, however, reflex actions were "physiological responses to more or less definite stimuli, and which involve rather the several organs of the organism than the activities of the organism as a whole" (1890-1, p422). Though there was no need to infer that the animal was conscious in order to understand reflexive behaviour, such behaviours might nonetheless, Morgan argued, be accompanied by consciousness. Instinctive behaviours differed from reflexive ones in their being "coordinated activities which are performed [...] in adaptation to certain circumstances, oft-recurring or essential to the species" (p422-423). Such activities included "perfect" instincts, which, for Morgan, included the chick's ability to accurately peck at objects just moments after hatching, and "incomplete" instincts, which required some practice and development, but very little learning. Morgan claimed that such incomplete instincts or habitual activities were "accompanied by consciousness during 
the process of their organization and establishment" (p432), but once the behaviours were developed, they occurred without or with very little consciousness (p431). Perfect instincts, like reflexes, might be accompanied by consciousness, but attributing consciousness would be unnecessary for understanding the relevant behaviour. What Morgan called "intelligent" actions, on the other hand, most definitely required the operation of consciousness. These were behaviours that were learned in adaption to special circumstances, and hence peculiar to individual animals. Like Romanes, Morgan now thought that learning from experience was a sufficient (but not a necessary) behavioural indication of consciousness: "all of these [i.e., reflexes, instincts, and intelligence] may be, and the last, the intelligent actions, invariably are, accompanied by consciousness" (p432).

This marked a very significant change in outlook from his earlier work, for, as we saw, it was for adopting exactly this sort of psychological approach to framing the explanatory posits of comparative psychology (rather than a purely behavioural one) that the earlier Morgan criticized Romanes. While this new Morgan was under no illusions about the practical difficulties of determining whether particular animal behaviour was due to reflex, instinct, intelligence, and so forth, these were perfectly legitimate objects of investigation for the comparative psychologist.

Where the main disagreement existed between Morgan circa 1890 and Romanes was the distinction between reason and what Morgan was now calling "intelligence", and whether there was good evidence for reason in animals. Both men understood reason to involve the ability to engage in abstract conceptual thought. Creatures endowed with such capacity — human beings, for instance — could carve up the world using various concepts by which they could think about objects and situations in ways removed from immediate sensory experience. However, Romanes tended to regard any instance of individual learning from experience as an example of such rational capacity at work. Take the example of a dog learning to take the current of a river into account when swimming across it. Romanes explained cases like this in terms of the animal having acquired a conceptual understanding of the relationship between means and ends-i.e., an explicit understanding, independent of immediate sensory experience, of the river current, how it affected the path of a swimmer across the river, and thus of the best place to enter the 
river to get to its desired landing point. Morgan, however, thought that there was a vast realm of individual learning from experience that fell short of genuine reason. For instance, the dog could, through a process of trial and error, have learned an association between entering the water at a particular spot with ending up in the mud and an association between entering at a point higher up stream with reaching a more desirable landing spot (p364-365). While such trial and error learning certainly required the operation of consciousness, it need not involve any abstract conceptual understanding of the river current and its effects on a swimmer. It only required what Morgan called the "perceptual" capacity to adjust one's behaviour according to one's past and current perceptions - for instance, to the associations between events that one has observed over time. Such instances of non-conceptual learning from experience, Morgan dubbed "intelligence".

This was a crucial distinction, and one of Morgan's most important theoretical contributions to comparative psychology. Associationist theories of learning had, of course, a long pedigree in British philosophy, and earlier psychologists like Alexander Bain had been busy trying to understand how such learning might work in the brain (see Boakes, 1984). What Morgan was doing, however, was showing how various forms of associationist learning could be distinguished from the kind of conceptual, abstract understanding of relations that was central to both Romanes and Morgan's notion of reason. With this distinction in hand, Morgan expressed scepticism about Romanes' evidence for reason in animals. In what one might regard as a precursor to his famous Canon, he argued that we should "assume that the [the animal's] inferences are perceptual, unless there seem to be well-observed facts which necessitate the analysis of the phenomena, the formation of isolates, and therefore the employment of reason" (p362-3). Morgan discussed a sampling of the supposed evidence for animal reason, and maintained that the there were no grounds to hold in any case that the relevant behaviour was the product of more than merely intelligent adjustment of behaviour.

Morgan was thus able to retain his theoretical view that language was necessary for reason, and hence that language-less animals were bereft of reason. However, his discussion of questions of animal mind had quite a different tone to that found in his earlier papers. His invoking of the interpretive principle described above, whereby, other 
things being equal, one was to prefer merely intelligent, perceptual explanations of animal behaviour to explanations that involved the attribution of reason and conceptual capacity, provides a clear illustration of this. Morgan argued for caution when explaining behaviour, but he did not want to give up on theorizing about the internal psychological states of animals. To the contrary, he was now quite happy to attribute particular behaviours to intelligence (as he now defined it) and other genuinely psychological processes. $^{9}$

The changes in Morgan's position were not lost on Romanes. In his 1891 review of Animal Life and Intelligence, Romanes observed: "Prof. Morgan has now abandoned the extreme scepticism which characterised his writings of some years[...] His criticisms now are confined to questioning the validity of inferences in particular cases - such as whether activity A on the part of an animal is due to emotion $a$, or not rather to emotion $b$. So far as these detailed criticisms apply to my own writings [...] I willingly allow their cogency" (1891, p263-264).

\section{Morgan's developing epistemological views}

In stark contrast to Morgan's earlier work, Animal Life and Intelligence can therefore be seen as an attempt to strengthen Romanes' project by introducing a clear distinction between reason and intelligence, and clearer understanding of what kind of evidence was necessary to establish the presence of reason in animals-thus, representing a full acceptance of the idea that a genuine science of animal minds was indeed possible. But, why exactly did Morgan shift from a position of "extreme scepticism" about the study of animal minds to this more optimistic position?

In his autobiography, Morgan (1930, p237) said that he was introduced to philosophy as a youth by the rector of his local parish, who encouraged him to read Bishop Berkeley. Richards (1987, p382-385) speculates that it was Morgan's early infatuation with Berkeley's claims about the fundamental isolation of the individual mind-of each person being locked inside their own consciousness-that partly motivated his epistemological scepticism about the science of comparative psychology.

\footnotetext{
${ }^{9}$ This softening of Morgan's position is evident in Morgan's thinking from around 1888 onwards. For example, in an unpublished lecture notebook dated 1888-1891 (Conwy Lloyd Morgan Papers, University of Bristol Information Services, Special Collections, DM 612).
} 
Richards argues that Morgan gradually shifted away from this sceptical stance as his monistic views on the mind-body problem developed over the course of the mid-to-late 1880s (see also Wozniak, 1997). He suggests that three factors converged to bring about this shift: first, through their exchanges (see especially, Romanes, 1884), Romanes managed to convince Morgan that his sceptical arguments against Romanesian psychology could equally apply to human psychology; second, Morgan came to see his own idealism as metaphysically excessive. A third factor, Richards argues, was Morgan's experimental research into animal instincts.

Though we dissent from some aspects of Richard's account, we agree that Morgan underwent an important shift in epistemological outlook coincident with the development of his monism, and it was this that encouraged the rapprochement with Romanes in Animal Life and Intelligence. In this section, we will draw out the nature of the change in epistemological outlook that Morgan had undergone by 1890, and explain why this encouraged much greater sympathy to an ejective approach to comparative psychology. In particular, we will highlight an aspect of Morgan's work that has attracted very little previous attention: his philosophy of science. ${ }^{10}$ In the next section, we will discuss the impact of Morgan's experimental work. As we will show, this took Morgan in yet another direction, this time away from Romanes, towards a distinctively new vision for comparative psychology.

Though they came in many different varieties, monistic philosophies were all the rage in mid-to-late nineteenth century philosophy. At the core of all monistic theories of mind and body was a rejection of Cartesian substance dualism, and a rejection of the notion that mind and matter could exert causal influence on each other, either in one direction or the other. From there, however, monists could go in a variety of different directions, including to various kinds of idealism, materialism, and the neutral monism of the German polymath, Ernst Mach. ${ }^{11}$ The kind of monism that Morgan adopted in Animal Life and Intelligence was a dual-aspect monism. According to dual-aspect monisms, mind and matter were regarded as different phenomenal manifestations of the same

\footnotetext{
${ }^{10}$ Kimler (2000) describes some important aspects of Morgan's philosophy of science. Our account of how it fits in with Morgan's broader intellectual development is rather different to his.

11 Around the time that Morgan was writing Animal Life and Intelligence, Mach was involved in discussions of his own monism in the pages of the new American philosophy journal, The Monist, to which Morgan also became a regular contributor.
} 
underlying substance (though different dual-aspect theorists provided quite different accounts of the nature of this underlying substance). Thus, even though they were represented to us differently in experience, the relationship between them was one of fundamental identity. Such views had their roots in Spinoza, whose work Morgan had also been introduced to by the kindly rector (Morgan, 1930, p238). By the late 1870s, some version of dual-aspect monism had been adopted by many of the scientific philosophers developing the new sciences of the mind, including Ernst Haeckel, Gustav Fechner, and Wilhelm Wündt in Germany, and W.B. Carpenter, George Henry Lewes, and W.K. Clifford in Britain. ${ }^{12}$ The prevailing view amongst these theorists was that dual-aspect monism was the only metaphysics that could underwrite a true science of the mind, since it allowed that mental and neurological processes could be studied as concomitants of each other. ${ }^{13}$

Such views were still highly controversial, however, in large part because they were frequently associated with obscure speculative accounts of the underlying nature of reality. Haeckel and Fechner, for instance, held a rather mystical panpsychism, according to which every speck of matter had a mental side to it. Clifford $(1874,1878)$ caused a stir in Britain by arguing that the fundamental substance making up all reality was "mind stuff', unconscious psychical particles, which, when arranged in the form of a complex nervous system gave rise to conscious thought, but when the object of sense experience were represented as matter. However, like Wündt (to whom Clifford [1878, p87-88] compared his own views), Clifford dismissed panpsychism. He argued that consciousness

\footnotetext{
${ }^{12}$ Morgan cited both Spinoza and Clifford in Animal Life and Intelligence (Lewes and Haeckel were also cited, albeit not in the context of the mind-body problem). He made no mention of Fechner or Wündt, instead citing another German, Max Müller, as a key influence on his thinking (1890-1, p467). Morgan did, however, use Fechner's analogy of the concave and convex sides of the same circle to illustrate the relationship between mind and body, though both Lewes and Carpenter had also used it. Richards (1987), somewhat inaccurately, suggests that Morgan's monism was similar to the neutral monism defended by Mach and William James. For the differences between neutral monism and dual-aspect views, see Mach (1886) and James (1905).

${ }^{13}$ Cartesian substance dualism was seen as facing a fundamental problem in accounting for mind-body interaction, while Leibnizian psycho-physical parallelism needed to explain how mind and body could be synchronized, and materialism was seen as either dismissing mind altogether or demoting it to a merely epiphenomenal by-product of neural activity, as on Huxley's (1874) conscious automata theory.
} 
likely only emerged when mind stuff was composed in the form of something like a nervous system. ${ }^{14}$

As Richards documents, Romanes had also been developing a dual-aspect monism during the $1880 \mathrm{~s}$, though the path taken was somewhat circuitous. Romanes ultimately committed himself to Clifford's mind stuff theory, ${ }^{15}$ but remained much more open to Fechnerian panpsychism, granting the possibility that, since mind stuff was at the root of everything, societies, or even the universe as a whole, may have conscious mental states.

In his 1885 book, The Springs of Conduct, Morgan expressed uncertainty about the proper solution to the mind-body problem. Though he regarded what he called "materialism"- which he described as the view that conscious mind was simply an attribute of certain kinds of matter in motion - as "the practical answer", perfectly adequate for the purposes of the practical man of science, his philosophical leanings were towards Clifford's mind stuff monism. Though he referred to this theory as a kind of "idealism", he recognized that it was not much like the idealism of Berkeley, since the ultimate stuff of reality was not conscious thought, and it did not involve regarding talk of matter and material objects as a roundabout way of talking about sensory experience (he expressed no view on the issue of panpsychism).

Despite these metaphysical speculations about mind stuff, Springs of Conduct presented quite an austere empiricist epistemology when it came to scientific questions. The ultimate test of truth in science, Morgan argued, was empirical verification. This notion was tied squarely to successful observational prediction, or "prevision". Rejecting Cartesian notions that the ultimate test of truth for ideas about the empirical world was the clarity and distinctness of the relevant idea, or the inconceivability of its negation, Morgan asked:

\footnotetext{
${ }^{14}$ Though they were often less than clear on this point, the scientific dual-aspect monists generally did not accept the view attributed to Spinoza, and adopted by British idealists like F.H. Bradley, that the universe contained only one particular thing and thus that there could exist no genuine relations between individual things. This view, famously criticized by Bertrand Russell and G.E. Moore at the turn of the twentieth century (partly precipitating the rise of analytic philosophy), was inimical to a science of psychology that sought to chart mental and physical relations.

${ }^{15}$ Many of Romanes' essays on the topic were collected together in a posthumous volume, Mind, Motion, and Monism, edited by Morgan (Romanes, 1896). Alongside Clifford, Lewes and Wündt were mentioned several times in these essays.
} 
$[\mathrm{H}]$ ow is it that self-evidence of a fact or the inconceivableness of its negation comes to be the test of truth? Surely because throughout all experience, individual and ancestral, there has been no contradiction of the fact, no negation of its truth. Or, to put it in another way, surely it is simply because prevision has been constantly verified? Self-evidence and the inconceivableness of negation are simply the organized outcome of experience constantly verified, and only as such have they any value as the test of truth for external facts.

For all practical purposes, I take it, prevision is the most valuable test of truth. (1885, p236, emphasis in original).

As an example of the test of prevision at work, Morgan argued that the Darwinian theory of common ancestry deserved to be regarded as a true theory because so many of the observational predictions deduced from the theory "may be fairly regarded as fulfilled predictions; and in this fulfilment of prediction the doctrine of descent stands justified by the test of truth" (p250). This particular passage might be taken as evidence that Morgan's philosophy of science was hypothetico-deductivist, in contrast to the prevailing inductivism established in nineteenth century British philosophy of science by J.S. Mill, John Herschel, and William Whewell. However, Morgan clearly thought that hypotheses ought to be grounded in observation before the test of prevision was applied. His views remained very much in the inductivist tradition, therefore.

We submit that it was Morgan's early, quite austere, empiricist philosophy of science, with its emphasis on observational verification as the touchstone of empirical justification that, in conjunction with the Cliffordian conception of the ejective method, led Morgan to scepticism about the possibility of a science of animal minds. As he stated in an earlier part of the book in direct opposition to Romanes:

A science of ejecto-subjective human psychology is therefore possible, because you and I and all who are capable of introspection can compare and verify - each for himself in his own experience - the results obtained by psychologists. But my faithful dog, if he be capable of introspection, cannot convey to me the results at which he has arrived. In the psychology of animals no such verification is possible, and verification is that which makes science science. (1885, p164-165).

Of course, this epistemological attitude was seemingly just as out of step with the Cliffordian "mind stuff" theory to which Morgan expressed sympathy only a few pages later - a theory beyond the test of prevision if ever there was one - though, at this point in 
his career, Morgan did seem happy to accept the legitimacy of speculative metaphysics, ${ }^{16}$ and draw a distinction between the methods of science and those of metaphysics. In any case, it seems that Morgan did come to regard the mind stuff view as epistemologically unfounded, since in Animal Life and Intelligence, he abandoned all speculative claims about the nature of the underlying substance of reality, as well as his pragmatic sympathy for materialism. Instead, a much more metaphysically modest, but clearly much thought over, monism reigned supreme: mind and matter were to be regarded as two aspects of "the unknown substance of being - unknown, that is to say, in itself and apart from its objective and subjective manifestations" (1890-1, p468). Conceptually, mind and matter were both "constructs": products of the analysis of experience-mind from experiences of one's own consciousness, and matter from sense experience. Neither had greater claim to reality than the other. Rather, they were to be regarded as different aspects of the same underlying noumenal reality, like the concave and convex sides of the same circle. In a Kantian spirit, Morgan argued that this reality was not directly knowable in itself, since it could not be an object of perception. However, good grounds did exist for believing in its existence and, with it, in the reality of both "matter" and "mind".

Morgan's primary argument for monism was that it led to "the most consistent and harmonious results" (p469). In keeping with his core commitment to empiricism, Morgan repeatedly emphasized that the grounds for all knowledge was experience and rejected the view that monism was to be based on a priori metaphysical speculation. Rather, all philosophies had to rest on certain assumptions - no theory of reality or knowledge could be built without assumptions of some sort. The question was which set of assumptions enabled us to produce the most coherent overall picture that was consistent with experience. Quoting T.M. Herbert, Morgan argued against materialism on the grounds that it faced a fundamental problem in accounting for mental causation. The idea that mind was a simply by-product of certain types of neural activity suggested that mental activity itself played no causal role in human behaviour, and that (in Herbert's words) "the actions, words and gestures of every individual of the human race would have been exactly what they have been in the absence of mind" (p471). But, that was an

\footnotetext{
${ }^{16}$ At the beginning of the section in which Morgan defended the mind stuff theory, he quoted Goethe: "Man must always in some sense cling to the belief that the unknowable is knowable, otherwise speculation would cease" (1885, p208).
} 
"absurdity", particularly since it implied that mind could have had no influence on the course of organic evolution. ${ }^{17}$ Idealism led to a similar lack of harmony with experience: "The world we live in is a world of phenomena; and it has a phenomenal reality every whit as valid as the noumenal reality which underlies it" (p474). Regarding the world of material objects as nothing more than states of consciousness was therefore just as out of sync with experience as regarding states of consciousness as mere by-products of material processes.

This left us with monism. Morgan followed Clifford in rejecting panpsychism and claims of a society- or world-eject as unwarranted, since our knowledge of consciousness was limited to it being "the metakinetic [mental] concomitant of a highly specialized order of kinesis [physical activity]", namely something like the "molecular processes" in the human brain (p467). However, he made no mention of mind stuff, and was distinctly unwilling to speculate about the nature of the noumenal things in themselves at the root of the two sides of mind and matter. Experience gave us reason to believe in a noumenal reality, but no grounds for claims about its intrinsic nature.

Though opposition to pure metaphysical speculation can be found throughout Morgan's writings - in his 1887 paper, "The generalisations of science", for instance, Morgan came very close to a Humean account of natural laws-Morgan was here becoming more consistently anti-metaphysical, befitting his empiricist heritage. However, as the structure of his argument for monism demonstrates, while, on the metaphysical front, Morgan's empiricism had become more conservative, in his philosophy of science, Morgan's empiricism had become much less austere. The notion of what Morgan called "congruity" in systems of ideas had attained great epistemological importance for him as a test of truth, in addition to direct empirical verification. To appreciate this change more fully, we need to look at his theory of cultural evolution.

The argument for monism was presented in the first half of the last chapter of Animal Life and Intelligence, entitled "Mental Evolution". The second half of the chapter was concerned with a different problem: how to account for the evolution of human

\footnotetext{
${ }^{17}$ Here, T.H. Huxley's modus ponens was Morgan's modus tollens: while Huxley had embraced the idea of humans and animals simply being conscious automata as a consequence of the kind of view that Morgan called "materialism", Morgan saw this as a reductio of the materialist view. Romanes (1882b) had also given causal-evolutionary arguments of this kind against materialism, following Clifford (1874) and James (1879).
} 
culture and ideas. Morgan held that natural selection could not have played a significant role in the development of human culture since many of our thoughts, concepts, and ideas - particularly aesthetic and scientific ones — were "unassociated with life-preserving and life-continuing activities" (p485). "It matters not how a man explains the lightning's flash", Morgan argued, "so long as he avoids being struck" (p483). Rather, a different kind of evolutionary process was required, which he went on to elucidate. Cultural evolution, Morgan argued, was driven by a basic psychological law built into the individual human mind: that individuals accept or reject an idea according to how "congruous" or "incongruous" it is with the individual's internal mental environmenti.e., with "the system of ideas that among which it is introduced" (p486). It was against this internal mental environment that particular ideas were selected or eliminated in the individual mind, and since the conceptions of "a tribe, nation, or other community, are simply representative, either of the general views of the majority of the individuals, or more frequently of a majority among a cultivated minority" (p486-7), the same process could be used to explain the evolution of systems of ideas at these higher levels. ${ }^{18}$ Because the creative ability of human beings to produce new ideas led to natural variation, and because there were many possible ways to make systems of ideas internally congruous, the diversity of human cultures was fully explicable.

Importantly, Morgan proposed "the law of congruity" as a test for truth in both a psychological and a normative sense: not only was it the principle of mental selection at work in the human mind that could explain human cultural evolution, it was also to be seen as a normative epistemological principle that ought to guide all human investigation, including both science and philosophy. Crucially, Morgan argued, "[o]nly one interpretation of nature can be true":

\footnotetext{
${ }^{18}$ Since Morgan's monism required that psychological and neurological processes be but two aspects of the same underlying process, Morgan highlighted what he regarded as the neurological concomitant of the psychological process of selection by congruity and elimination by incongruity: "Just as no idea can get itself accepted if it be in incongruity with the system of ideas among which it is introduced, so too, can no neural process become established if it be not in harmony with the other neural processes of the cerebral hemispheres...the environment of any neural process is constituted by other neural processes" ( $\mathrm{p} 490-491$, emphasis in original). Though science currently lacked the ability to distinguish "[t]he brains of Kaffir and Boer, of ploughboy and merchant, of materialist and idealist", their cultural and ideological differences must nonetheless, Morgan argued, be accompanied by neurological differences.
} 
[T] he winning species among systems of ideas and interpretations of nature are those in which the greatest number of ideas are fused into harmonious synthesis; in which all the ideas are congruous, few or non neutral; and in which the abstract or conceptual ideas, when brought into contract with concrete or perceptual states of consciousness, are found to be in harmony and congruity therewith. (1890-1, p493-494).

Thus, though the search for congruity had the potential to lead to great diversity, and the elimination of the false was "a slow and gradual process", taken to its fullest extent, the process would lead to us the truth. The key epistemic anchor here was congruity with perception, and it was this that set apart the interpretation of nature provided by science from that of other, more primitive systems of ideas. While other systems may achieve a high degree of internal congruity, science obtained epistemic superiority in virtue of both internal congruity and greater congruity with the results of observation.

Morgan developed these epistemological ideas further in a follow up paper entitled, "The law of psychogensis", published in Mind in 1892. Here, Morgan also advocated congruity as "the law of right", that is to say, as a principle for deciding among different ethical beliefs. Morgan's epistemology was therefore now decidedly naturalistic, in that the methods of philosophy were to be continuous with the methods of science. $\mathrm{He}$ also chastised what he called the "metaphysical mind", for failing to see the importance of congruity with perception.

In his normative claims, Morgan was by no means recanting his commitment to empiricism. Rather, he was now explicitly articulating a more sophisticated form of empiricism, echoing some familiar, albeit still controversial themes in mid-to-late nineteenth century philosophy of science. William Whewell (1858) had advocated "coherence" as a test for truth in scientific theorizing, in addition to successful prediction. Whewell's notion of "consilience" - of multiple different lines of evidence leading one to the same conclusion - was connected with this idea. Kimler (2000) notes the influence that the notion of consilience had had on British evolutionists, most notably Darwin in his thinking about, and presentation of, the nature of the evidence for evolution by natural selection. Coherence as a test of truth was also central to the logic of F.H. Bradley (1883) (though Bradley's broader epistemological and metaphysical views were far removed from Morgan's empiricism), and such views seem to have been widespread in monist 
circles - the editor of The Monist, Paul Carus, advocated a similar test of truth to Morgan's in a paper entitled, "The criterion of truth" (1891). The fact that Morgan's view was part of a broader evolutionary epistemology made his contribution much more original, however-making it even more of shame that Morgan's work in this area has been almost entirely forgotten.

One shouldn't see this emphasis on congruity or coherence as completely new in Morgan's work. Echoes of it can be found in his earlier work, including his discussion of the evidence for evolution by natural selection in The Springs of Conduct. Moreover, at least since his earliest interactions with Huxley at the Royal School of Mines (see Richards, 1987), Morgan had been steeped in the Darwinian argument style. However, these notions were now receiving much greater and more explicit emphasis in his writing, and the philosophy of science he was now articulating stands in stark contrast to the more austere verification-centred approach he explicitly presented in Springs of Conduct, which infused his sceptical discussion of comparative psychology.

It is easy to see how this more sophisticated form of empiricism could be much friendlier to attributions of particular psychological processes to animals as part of a search for most "congruous" explanation for behaviour. One did not need direct observational verification to take particular psychological explanations of animal behaviour seriously. Indeed, in later work, Morgan (1899) suggested that psychology faced no greater epistemological problems than physics—quite a reversal from his earlier pessimism about the problem of other minds.

\section{Morgan's experimental turn}

Though there were significant theoretical differences between Morgan and Romanes, methodologically, Animal Life and Intelligence, was very much in the Romanesian mold. Morgan urged caution in the interpretation of anecdotal evidence and expressed scepticism about the existence of reason in animals, but, like Romanes, Morgan mostly seemed to accept the view that comparative psychology was a largely theoretical endeavour, best served by making clear distinctions between different psychological processes, and attempting to provide a grand synthesis of all the behavioural data available, which, for the most part, remained in the form of anecdotal reports. Hence, the 
method was one not too different from the method of Darwin and other naturalists of the period.

However, soon after the publication of the book, Morgan began to specify, and carry out, an approach that was quite different to the Romanesian one. In his 1892 paper, "The Limits of Animal Intelligence" (1892c), ${ }^{19}$ Morgan reiterated his theoretical view about the dependency of "reason" on language, and explained that it was because of this that he strongly suspected that animals must therefore lack reason. However, as he had in Animal Life and Intelligence, and in stark contrast to the Morgan of the 1880s - who had asserted that the ascription of reason to language-less animals was an elementary category error, and, in any case, not something that could be defended on empirical grounds - in this paper, the issue of whether or not reason was exclusive to humans and fundamentally tied to language was definitely not one to be settled a priori, nor was it beyond the epistemic reach of science. But, unlike in Animal Life and Intelligence, Morgan was now much more specific about the kind of empirical approach he thought should be adopted in order to settle this important question:

I have conducted from time to time experiments with the object of ascertaining how far there is evidence in the dog of true cognition - of causation for example. I am inclined to believe as a result of my observations that there is nothing beyond a simple awareness of the causal nexus. But I am far from wishing to dogmatize in the matter. I am chiefly concerned that the phenomena should be carefully observed, and that experiments should be conducted on definite scientific lines. (1892c, p417).

Here, Morgan clearly came out as an optimist about the ability of a science of animal minds to get at the nature of the psychological causes of behaviour through careful experimentation. The question of whether a legitimate science of comparative psychology was possible was not at issue here; it was taken for granted that such a science was indeed possible. Moreover, this was a science not just of the externally manifested "habits" and "activities" of animals, but of the actual psychology underlying such behaviours - thus, the question of whether or not animals were actually capable of reason ("true cognition")

\footnotetext{
19 This paper was a response to commentary on his address to the 1892 International Congress of Experimental Psychology (Morgan, 1892a), in which Morgan first presented the Canon.
} 
was one that could be addressed through "accurate, and, as far as possible, crucial experiment and observation" (ibid).

This interest in experimentation was not entirely new. For example, one of Morgan's early forays into comparative psychology was a series of papers published in 1883 , reporting a variety of experiments that challenged the common belief that scorpions in distress would commit suicide by stinging themselves (1883a,b,c). Romanes reported apparent instances of this behaviour in Animal Intelligence, but stated that the reports "demand further corroboration" (1882, p225). Morgan noted that such apparently maladaptive behaviour was all the more interesting as it could be seen as challenging the theory of evolution by natural selection. Working in South Africa at the time, Morgan thus performed a series of methodical, but gruesome experiments, to test the accuracy of these reports $(1883 \mathrm{a}, \mathrm{b}, \mathrm{c})$. First, he used slides to focus light on the scorpion's back, burning the scorpion. While the scorpions subjected to this procedure inevitably died, it was not from stinging themselves, but from burning to death (1883a, p20). Other methods included slowly heating the scorpion in a bottle, surrounding a scorpion with fire, burning phosphorous on their backs, and exposing them to sulphuric acid (ibid, p21-22). ${ }^{20}$ In no case did a scorpion ever commit suicide.

The work with scorpions clearly indicates an early belief that experimentation could provide important information about animal behaviour - in this case, whether a widely reported behaviour did in fact occur. However, the early Morgan notably did not use such experiments to make claims about the psychological qualities underlying the relevant behaviour. Consistent with the sentiments of the 1886 Mind paper, the emphasis was purely on studying the external aspects of the behaviour ("suicide" was defined purely in terms of self-stinging, not in terms of underlying motivation, for instance). When Morgan later changed his mind about the epistemic tractability of the ejective method, experimental results did become relevant to inferring psychological processes. For instance, Spalding's (1873) developmental experiments on the instincts of chicks played an important role in Morgan's discussion of instinct in Animal Life and

\footnotetext{
${ }^{20}$ The gruesomeness of the experiments apparently provoked outrage amongst some of his correspondents. In response, Morgan appealed to the gravity of the scientific question at hand: "But is the Theory of Natural Selection of sufficient importance in its bearing upon human life and human progress to justify the infliction of pain upon, say, sixty scorpions? I am one of those who believe that it is" (1883c, p530).
} 
Intelligence (more on this shortly). Morgan also cited John Lubbock's (1777, 1882) behavioural experiments with ants and other social hymenoptera, and reported some experiments of his own (see, e.g., Morgan, 1890-1, p352). However, at this point, Morgan's references to experimental work were, like those of Romanes, largely in the form of cursory asides, discussing interesting observations that had to be accommodated into a bigger picture, alongside a mass of anecdotal evidence. Sustained experimental work was certainly not picked out as a primary mode of investigation. ${ }^{21}$ In the years immediately after the appearance of Animal Life and Intelligence, however, Morgan came to advocate a thorough-going experimental, and, particularly, developmental, approach to answering the big questions in comparative psychology.

In an essay also titled "The Limits of Animal Intelligence", published in 1893, Morgan returned to the theoretical differences between "instinct", "intelligence", and "reason", with reference to a series of experiments he had conducted with newly hatched chicks. Once again, Morgan followed Romanes rather than his earlier self by framing these notions in psychological rather than purely behavioural terms. For example, in distinguishing between "intelligence" and "reason", Morgan invoked the notion of consciousness:

[F]or intelligence it is sufficient that what we call the relationships of natural objects should be felt on the margin of consciousness, inalienably associated with the objects themselves, while for reason it is necessary that relationships should be so far dissociated from the objects as to occupy the focus of consciousness. (1893, p233).

\footnotetext{
${ }^{21}$ Romanes' attitude towards experimental work was remarkably ambivalent. He also reported Spalding's and Lubbock's work, along with some rudimentary experiments of his own. However, he doubted that such controlled experimental investigation of animal behaviour had much capacity to inform us about the minds of animals:
}

[I]n the science of psychology, nearly all the considerable advances which have been made, have been made, not by experiment, but by observing mental phenomena and reasoning from these phenomena deductively. [...] No one can regret more than myself that the most interesting of all regions of scientific enquiry should happen to be the one in which experiment, or inductive verification, is the least of all applicable. (1883a, p12).

As Boakes (1984) notes, this scepticsm about experimental methods in comparative psychology stands in interesting contrast to Romanes' own pioneering experimental work in physiology and embryology (Romanes, 1880, 1883b). 
Morgan's experiments concerned the development of various pecking behaviours in chicks. Morgan kept the chicks in an incubator in his study without any contact with adult birds, and recorded his observations of them over the course of several days after hatching. Against the prevailing view - the one that he had himself advocated in Animal Life and Intelligence, on basis of Spalding's results - that the chicks' pecking behaviours - such as their ability to peck accurately at food and to discriminate between "a nice [tasting] worm and a nasty [tasting] caterpillar" (1893, p234)—were entirely innate and purely instinctive, Morgan argued that such behaviours in fact developed with the guidance of intelligence. For instance, though the chicks seemed to automatically peck at things immediately after hatching, they did not skilfully seize and swallow pieces of food at first, but had to refine their skills over time. They also had to learn to avoid "nasty" caterpillars and prefer "nice" worms by tasting them first. In such cases, Morgan argued, "we have in elementary form the basis of intelligent adaption to circumstances". The latter case, in particular, "involves the association of impressions and ideas; and it implies a power of control over the motor responses" (p234).

In the Introduction to Comparative Psychology, published a year later, Morgan reported the results of these and other similar experiments he had conducted, emphasizing the importance of such "systematic and sustained" observations of animal behaviour, even if their results might run against conventional wisdom or the impressions one got from more casual observation:

I would, however, urge on all those who have the good fortune to witness the performance of some conspicuously intelligent action in any animal, not to rest content with merely recording it, but to make it the basis of further observation direct to the end of ascertaining its true nature. The records of casual observation are not without their interest; but the result of detailed investigation are, for comparative psychology, of far greater value. (1894c, pxii).

Such calls were repeated many times throughout the book, with Morgan frequently claiming that behavioural experiment should be the key investigative tool for comparative psychology: the central questions in the field, such as whether animals are capable of truly conceptual thought, "will have to be settled, if [they] can be settled at all... by carefully conducted experimental observations, carried out as far as possible under nicely controlled conditions" (1894c, p359). 
A key point of emphasis, for Morgan, was studying the developmental trajectory of particular behaviours (as he had with the chicks), since it was "quite impossible to get at the true psychological import of a complex and nicely adapted activity, unless we know something of its embryonic stages" (1894c, p251). Observing a skill only in its fully developed state - such as a dog using its head to open a latched gate, or a chick pecking at food with near perfect accuracy_could mislead us about the true nature of the behaviour-for instance, that it was product of reason, when it was actually the result of countless instances of trial and error, or a perfect instinct, when it was actually guided by intelligence. It was for this reason that Morgan advocated abandoning the practice of merely recording interesting chance observations of behaviour and instead carrying out intensive studies of animal behaviour over prolonged periods of time, and, as far as possible, manipulating various factors that may influence both the performance and development of behaviour. If researchers did this, Morgan argued, we would "gain a better acquaintance with the psychological processes in animals than we could gain by a thousand anecdotes" (1894c, p291). ${ }^{22}$ "In zoological psychology", Morgan wrote, "we

\footnotetext{
${ }^{22}$ Morgan's emphasis on carefully conducted experimental studies of behavioural development shouldn't be read as exclusively a call for highly interventive experiments of the sort he conducted with the chicks. $\mathrm{He}$ was also an advocate of more "hands off" observational studies, like those that he conducted with his dog, Tony (1894c, p287-290), into the genesis of Tony's ability to open a latched gate with his head. Here, it sufficed simply to conduct careful observation of the acquisition of the behaviour over time in order to establish that it was a product of trail-and-error learning (intelligence), rather than reason (e.g., a conceptual understanding of the workings of the latch). Indeed, Morgan (1898) later criticized many of Thorndike's (1898) experiments for being overly interventive and artificial, anticipating the concerns of later ethologists about the ecological validity of much laboratory work in comparative psychology:
}

The conductions of his experiments were perhaps not the most conducive to the discovery of rationality in animals if it exist [sic]. The sturdy and unconvinceable advocate of reasoning (properly so-called) in animals may say that to place a starving kitten in the cramped confinement of one of Mr Thorndike's box cages, would be more likely to make a cat swear than to lead it to act rationally. And he may further urge that where the string passes out of sight and the bolt is hidden from view, the opportunities of understanding the situation are excluded... But although I do not deem Mr Thorndike's method so conclusive for the anti-rationalist view as observation under more natural, and, I may add, more sympathetic conditions, yet the form of his curves affords no particle of evidence for reasoned behaviour. (Morgan, 1898, p249).

There is a direct parallel here with Morgan's criticisms of Romanesian comparative psychology: just as the anecdotal reports collected by Romanes and others failed to provide adequate evidence for attributions of reason to animals, so Thorndike's unnatural puzzle box experiments failed to provide fully adequate evidence for a denial of reason to animals. Morgan's call for experimental methods in comparative psychology was thus also a call for experiments that were actually capable of revealing (rather than inhibiting) the natural abilities of animals. 
have got beyond the anecdotal stage, we have reached the stage of experimental investigation" (1894c, p291).

In this respect, Morgan's methodological rhetoric was quite different to that of Animal Life and Intelligence, which was very much in "the anecdotal stage".

\section{The influence of Mann Jones}

Morgan's turn towards an experimental vision for comparative psychology can be seen in the context of wider trends in biology and psychology of the period towards experimental methods. This was a time when important evolutionary questions, such as questions about the nature of inheritance - the tenability of Lamarckian inheritance of acquired characteristics, in particular-were starting to be addressed with various experimental techniques. In an 1892 review of the French biologist, Henry De Varigny’s Experimental Evolution, Morgan praised Romanes-who had himself done pioneering experimental work in physiology and embryology (e.g., Romanes, 1880, 1883b) — for calling for an institution of experimental biology where one could conduct experiments "testing evolution hypotheses in all their bearings" (1892b, p25). Morgan added that such an institution should also include a "special branch" dedicated to the "experimental investigations in comparative psychology" (ibid). In the same review, Morgan also referenced the new marine laboratories that were springing up, where important embryological and neurobiological work was being done, and in "The scope of psychophysiology", published in 1894, Morgan referenced the new experimental work in psycho-physiology being done in Germany ${ }^{23}$ and the United States. He noted that except for “Galton's valuable psychometric observations" (Morgan, 1894b, p505), Britain was falling behind when it came to experimental work in psychology, and called for more work to be done along these lines in comparative psychology. Moreover, his call in the Introduction for comparative psychology to reach "the stage of experimental investigation" also suggests that Morgan had come to regard the use of experimental methods as a hallmark of a maturing science. Hence, the move to experiment seemed a

\footnotetext{
${ }^{23}$ The psycho-physiologists Fechner and Weber were mentioned by name earlier in the article. Wündt, who had set up the first psychological laboratory in 1873, was not, but Morgan was most likely aware of at least some of his work, if only through Romanes.
} 
natural part of Morgan's more general call for comparative psychology to professionalize itself.

However, an additional impetus for Morgan's turn towards experiment had come by way of a friend, who had a crucial influence on the character of Morgan's particular experimental vision. Shortly after publishing Animal Life and Intelligence, Morgan received a letter, which offered experimental evidence against the claims that he had made in the book on the basis of Spalding's work. For instance, Spalding had claimed that young turkeys innately recognized and became fearful when they heard the cry of a hawk, supposedly indicating some degree of innate knowledge, or innate associations. Morgan had concluded that chicks "come into the world prepared at once to perform complex activities" (1890-1, p424). The correspondent, T. Mann Jones, described the results of his own experiments, which ran against many of Spalding's findings. In particular, Mann Jones argued that Spalding's claim about the instinctive knowledge of young turkeys was "an unwarrantable assumption" (Morgan, 1894c, pxi). It was this letter that prompted Morgan's own chick experiments and provided an important catalyst and influence on his experimental vision for comparative psychology.

Little is known about Mann Jones and most commentators pass over him. ${ }^{24} \mathrm{He}$ lived in Northam, Devon, and from 1865 to 1870 studied metallurgy at the Royal School of Mines (which Morgan also attended from 1871 to 1874). He was a Fellow of the Geological Society, and a Fellow of the Linnean Society of London. The Register of the Associates and Old Students of the Royal School of Mines and History of the Royal School of Mines (Reeks, 1920) also notes he had been a "professor of Chemical and Physical Sciences in the Oxford and Woolwich Common Military Colleges", and that he "engaged in research upon the Mind in Animals". The only publication listed in this register is a note published as Appendix D to Spencer's Justice (1892). He also published a variety of short letters and notices in journals, and his experiments are discussed not only by Morgan and Spencer, but also in Mills' The Nature and Development of Animal

\footnotetext{
24 Boakes (1984, p34) does note that Jones encouraged Morgan to approach Spalding's findings with caution, and Gray (1963, p336) notes the importance of Jones' influence, going so far as to say that were it not for Jones' influence on Morgan in questioning Spalding, there would have been no Thorndike.
} 
Intelligence (1898), which includes a letter from Jones detailing experiments he performed with young chicks in 1872 and 1873 . He died in $1899 .{ }^{25}$

Morgan first mentioned Mann Jones in the review of de Varigny's Experimental Evolution for Nature (1892b). De Varigny claimed that kittens are afraid of dogs the first time they smelled them. This view was supported by Spalding's earlier experiments, but Morgan doubted such claims: "a careful observer, Mr. Mann Jones, writes to me that a young kitten with which he experimented 'took eight days to connect the smell or odour of his hand with the thing- $\operatorname{dog}$ "' (p25). Morgan then noted that his own observations supported the claims of Mann Jones.

In 1894, Morgan again credited Mann Jones for using developmental experiments to challenge the received view concerning a variety of animal behaviours in two separate publications: "Instinct and Intelligence in Chicks and Ducklings" and "The Scope of Psycho-Physiology". In the former, Morgan noted that Mann Jones' observations were contrary to Spalding's celebrated findings:

In my Animal Life and Intelligence I quoted some of Spalding's statements as to the intelligence of young birds. I then received a letter from my friend, Mr. T. Mann Jones, informing me of observations of his own which did not accord with those which I quoted, and expressing some scepticism as to the existence of what he termed "the philosopher's chick." I therefore determined to observe for myself, and the following paper contains some account of my observations[...] I desire to express my acknowledgments to Mr. Mann Jones for his suggestions and criticisms. (1894a, p207).

In the "The scope of psycho-physiology", Morgan credited Mann Jones for convincing him of the value of the experiments for comparative psychology:

Observations which I have made on newly-hatched chicks and ducklings stimulated thereto by suggestions from my friend Mr. T. Mann Jones, have convinced me that there is a wide field for careful experimental work on the instincts and the dawning phases of intelligence in young animals. We must employ the experimental method if we would make further advance in the study of the mental faculties of animals. Is it too much to hope that the time is not far distant when there shall be established in England chairs of zoological and experimental psychology, the occupants of which shall have the direction of

\footnotetext{
${ }^{25}$ We are thankful to Wendy Cawthorne of the Geological Society for providing us with the date of Mann Jones' death.
} 
adequately equipped laboratories wherein systematic observations, on the lines I have indicated above may be conducted? (1894b, p505, emphasis added).

One might be tempted to write off Mann Jones' influence as a slight correction to Morgan's previous views. This would be a mistake. As the passage just quoted indicates, Morgan's interest in Mann Jones' experiments extended beyond simple corrections of facts about the instincts of kittens and chicks; these kinds of observations were central to Morgan's evolving ideas about how questions in comparative psychology could be answered, and it is particularly noteworthy that Morgan followed up his acknowledgement of Mann Jones with the call for the establishment of "chairs of zoological and experimental psychology".

The early Morgan had called for comparative psychologists to study the "[t]he origin and mode of development of intelligent, that is specially adaptive actions and individual habits" (1886, p185-186), yet this what not seen as capable of telling us very much about the nature of the mental faculties behind the external behaviour. Mann Jones' experiments had shown Morgan how the study of behavioural development could indeed allow researchers to positively discover the role of consciousness and other internal psychological states, and, with it, how one could make definite progress on the big questions in comparative psychology. For example, with Mann Jones, Morgan argued that the pecking behaviours of chicks, which Spalding had claimed to be innate, were not the products of "instinctive knowledge" but were the products of "conscious control" (1894a, p213). In a similar vein, Morgan also came to see how detailed study of behavioural development could be used to answer the question of animal reason, such as whether it was because of the operation reason or mere intelligence (trial and error learning) that a dog learned to open a latched gate. Experiments to this effect, conducted on Morgan's own dog, Tony, were reported in the Introduction (1894c, p287-290). Here, Morgan emphasized that it might initially seem impossible to decide between rational and merely intelligent explanations for this behaviour. However, "when we know the whole history of it" (1894c, p290, emphasis in original), the question was much more tractable, and it was indeed possible to show that Tony's trick was the product of intelligence and not reason. 
Mann Jones' experiments were therefore important not just because they challenged the prevailing view about animal instincts; they showed Morgan how comparative psychology could progress beyond largely theoretical, synthesizing discussions of the sort found in Romanes' work, while directly challenging Romanes' scepticism of the value of experiments for understanding animal minds, and led Morgan to place great emphasis on the study of the development of behaviour. ${ }^{26}$ In his review of de Varigny, Morgan wrote, “such observations [i.e., Mann Jones and Morgan's own] lead me to look with suspicion on any arguments for the transmission of acquired characters based on supposed instinctive knowledge of things. And they show the need of further research in comparative psychology as could be carried out at the Institute of Experimental Biology" (p25). This hypothetical "Institute of Experimental Biology", Morgan envisioned, was the kind of place where an experimental comparative psychology could flourish. ${ }^{27}$

Nevertheless, though Morgan was here moving away from the Romanesian approach to comparative psychology, the new approach was compatible with the ejective method. In the Introduction, Morgan presented his mature account of how comparative psychology ought to be practiced. There, he made clear how one could marry the ejective method with experimental methods to determine whether or not a behaviour was instinctive, intelligent, or guided by reason. It is within this context that his famous Canon is to be understood.

\footnotetext{
${ }^{26}$ As Boakes (1984) notes, from a methodological perspective, Morgan's experiments- the chick experiments, in particular - now seem very crude, and Morgan (along with Mann Jones) seems to have misunderstood many of Spalding's claims, including the pioneering idea that the development of particular instinctive behaviours might depend on a critical period during which a stimulus must be presented.

${ }^{27}$ Morgan's reference to "the Institute of Experimental Biology", as well as his earlier quoted call for the establishment of "chairs of zoological and experimental psychology" in England, also indicates that he was deeply aware of the fact that there was very little by way of institutional support for the kind of research he was envisioning, certainly not in Britain. Like Spalding and Mann Jones, Morgan was an amateur experimentalist, conducting his work at home. What Morgan was envisioning required much more than the part-time efforts of gentleman scientists, or even of those like him with traditional university positions. It required institutes and laboratories with both the physical and financial resources necessary to keep large numbers of animals in the right kinds of conditions. Similar calls were being made in the US by early ethologists, like Whitman (see Burkhart, 1999). As Andrew Wilson (2002) has documented, that institutional support did not materialize in Britain, and thus, by the turn of the twentieth century, British experimental research in comparative psychology had lost any impetus it had thanks to Morgan's work. In the US, institutional support did eventually come for research in comparative psychology, but it was not for the kind of approach that Morgan envisioned.
} 


\section{A new method for comparative psychology}

In the preface to the Introduction, Morgan credited several researchers to whom he felt indebted. He mentioned that his views about reason and the perception of relations were based on the work of Herbert Spencer, and that he "borrows" William James' conception of consciousness (px). As for Romanes, he wrote that he "ow[ed] much, and in many ways." In a footnote, Morgan lamented: "The death of Professor Romanes, since this too brief acknowledgment of all that I owe him was written and printed, has entailed a loss to Science which is irreparable, and a loss to his personal friends which lies too deep for words" (px). Morgan then noted that various experimental results had changed his views on the development of putatively instinctive behaviour, and emphasized the importance of these sorts of "systematic and sustained" observations of animal behaviour for the future progress of comparative psychology. Once again, he noted that he had reported some of Spalding and Eimer's work on instinct in Animal Life and Intelligence, and recounted how, after receiving a letter from T. Mann Jones and repeating Jones' experiments, he came to doubt the findings of Spalding and Eimer. Morgan noted that he did not report all of Mann Jones' findings because he hoped that Mann Jones would publish them himself (pxiii)—which, it seems, Mann Jones never did.

Besides the emphasis on experimental over anecdotal observation, Morgan also emphasized the role of introspection in comparative psychology. However, Morgan worried that those studying comparative psychology were not well trained in its use:

It must not be forgotten that introspective psychology is an essential preliminary to comparative psychology, and that, if it is to produce results of scientific value, it must be based upon exact and oft-repeated observation. Such observation, however, requires special training, not less than objective observation in physics or in biology. It would be an inestimable boon to comparative psychology, if all those who venture to discuss the problems with which this science deals would submit to some preparatory discipline in the methods and results of introspective observation. (1894c, pxii).

This emphasis on careful training in "in the methods and results of introspective observation" came up again in chapter three, where Morgan laid out in more detail the 
epistemological and methodological problems facing the comparative psychologist and what he thought was the proper method for interpreting the minds of animals. ${ }^{28}$

Central to the methodology that Morgan laid out was what he referred to as a “double induction" (1894c, p47-48). The first, "objective induction", involved a detailed description of the observable aspects of animal behaviour, which required more than knowledge of the expression of the behaviour, but also knowledge of the animal's habits and normal activities (1894c, p48-51). The second, "subjective induction", required that one be familiar with one's own conscious experiences, by way of introspection. From facts about one's own consciousness, one could derive general laws of subjective experience. One could then use these general laws of subjective experience to theorize about how mind was involved in the behaviour one observed objectively-i.e., to make an ejective inference.

As he had in the 1880s, Morgan worried about such ejective inferences being vulnerable to error. He insisted that the psychologist be an expert at making objective inductions - that is to say, in observing and studying animal behaviour itself - but just as important was that the psychologist also be an expert in the making of subjective inductions:

Now it is idle to assert that one set of inductions is more important than the other, since both are essential. But there can be no question that the subjective inductions are in some respect more subtle and difficult and delicate than the inductions concerning objective phenomena.... And there can be no question that in the systematic training of the comparative psychologist the subjective aspect is not less important than the objective aspect. (1894c, p50, emphasis in the original).

[W] hereas the man who has to deal with animals for practical purposes can afford to be ignorant of psychological methods and results, the man who would deal scientifically with the psychical faculties of animals cannot afford to be thus ignorant. For the practical man accuracy of observation and careful induction therefrom are of primary importance, validity of psychological interpretation being for him altogether subsidiary. But for the scientific investigator thorough and accurate knowledge of and training in psychology is of at least co-ordinate importance with accuracy of objective observation. (1894c, p52).

\footnotetext{
${ }^{28}$ After the preface, Morgan included a prolegomena, which spelled out his dual-aspect monism about mind and body. Though there was a bigger focus on evolution as part of the argument for monism, not much of substance had changed since Animal Life and Intelligence. In chapters one and two, Morgan developed his theory of consciousness while borrowing an explicitly Jamesian terminology for it.
} 
We can regard Morgan's subjective induction as the process of coming up with candidate psychological explanations for the behaviour observed and then selecting which among them provided the best explanation for the observed behaviour-i.e., for the results of the objective induction. The "systematic training" that was needed here was one that inculcated an awareness of the range of potential psychological processes that could be at work behind a particular behaviour, which Morgan thought one could get through careful introspective analysis of the various sorts of processes that underlay one's own behaviours in various circumstances, and an understanding of how such processes could be differentiated as candidate explanations through close consideration of behavioural observations. This harked back to his earlier concerns about the ejective method in the 1886 Mind paper - that, even with human beings, one had to be careful not to assume that one's own thoughts and experiences were shared by others, hence, one had to be fully aware of the range of different possible psychological routes to the same observable behaviour - only now Morgan was much more optimistic about be able to move beyond this point. As became clearer in later chapters of the book, awareness of there being a range of different potential explanations for a given animal's behaviour meant that information about the developmental trajectory of particular behaviours was especially important as part of the objective induction, since it was here that one could most clearly see the role of different candidate processes (instinct, intelligence, and reason) at work, making the subjective induction to the best psychological explanation for the fullydeveloped behaviour that much easier. Therefore, once one brought together "systematic and sustained" observation of animal behaviour — especially of its genesis over timewith "knowledge of and training in psychology", one would be in a much better place to get at the true underlying psychology of the species in question. Either of these on their own would not be enough.

Crucial to Morgan's point about the necessity of training in introspective psychology was evolution. Morgan was very critical of researchers who, in his view, placed too much emphasis on the idea that Darwin's theory implied psychological similarities between other species and humans. Though Morgan did not explicitly direct his criticisms at Romanes in this context, it seems clear that Romanes was a target of such 
criticism. For Romanes, psychological continuity across the animal kingdom was both the key implication of the theory of evolution by natural selection for psychology and the epistemic guarantor for the use of the ejective method in comparative psychology: without this foundational assumption, analogical inferences from our (introspective) knowledge of the nature of the psychological causes of human behaviour to the psychological causes of animal behaviour would have no justification. Moreover, as in the case of Romanes' initial worries about being able to say anything about the psychology of invertebrates, whenever Romanes felt challenged to justify his confidence in being able to make substantive claims about the psychology of particular species based upon quite limited information about their behaviour, and in spite of his awareness that their life-ways were often so different to our own, this assumption of psychological continuity was brought to the fore.

Morgan agreed that Darwin's theory implied some measure of psychological continuity at the very broadest level: thanks to common ancestry and homologous neural structures, we could be sure that animals do possess minds and mental states. However, psychological similarities between species due to common ancestry should not be overemphasized at the expense of the other key part of Darwin's theory of evolution: diversity between species brought about by natural selection, which tailored organisms to their respective environmental niches:

[W]hy should the community [i.e. similarity] of psychical nature be greater than that of physical nature? ...The physical nature [of animals] being widely divergent from that of man, is it not reasonable to suppose that the psychical nature is, or at least may be, also widely divergent? (Morgan, 1894c, p40-41)

Later on in the chapter, Morgan argued that the theory of evolution predicted a view of the distribution of psychological processes in nature that he called the "method of variation", which led us to "expect that those mental faculties which could give decisive advantage in the struggle for existence would be developed in strict accordance with the divergent conditions of life" (1894c, p57). ${ }^{29}$ Thus, for Morgan, the broad degree of

\footnotetext{
${ }^{29}$ Morgan (1894c, p56-58) distinguished the method of variation from two other "methods" for thinking about the similarities and differences between humans and animals: the "method of levels" and the "method of uniform reduction". According to the method of levels, all animals share certain mental faculties, but only humans possess "higher" mental faculties: "thus the dog is just like me, without my higher faculties";
} 
psychological continuity implied by Darwin's theory was quite consistent with different species possessing very different mentalities, varying according to the different environmental challenges that they faced. ${ }^{30}$ Though Morgan would no doubt have said that Romanes was much more careful than many of his correspondents in this respect, Morgan was certainly directing his ire at least in part at Romanes when he drew attention to this neglected flip-side of the evolutionary process.

Given all of this, Morgan emphasized that comparative psychology needed more than just cursory interpretation of the available behavioural evidence. Interpretations needed to be informed by "knowledge of and training in psychology", which offered a range of different potential psychological explanations for a given animal's behaviour that one could then try to choose between. It was within this context that Morgan introduced the Canon:

For in the study of animal psychology as a branch of scientific inquiry, it is necessary that accurate observation, and a sound knowledge of the biological relationships of animals, should go hand in hand with a thorough appreciation of the methods and results of modern psychology. The only fruitful method of procedure is the interpretation of facts observed with due care in the light of sound psychological principles.

What some of these principles are we have considered, or shall consider, in this work. There is one basal principle, however, the brief exposition of which may fitly bring to a close this chapter. It may be thus stated:---In no case may we interpret an action as the outcome of the exercise of a higher psychical faculty, if it can be interpreted as the outcome of the exercise of one which stands lower in the psychological scale. (1894c, p53, emphasis in the original).

The italicized sentence is, of course, the Canon. However, we should not ignore the sentences preceding it. Comparative psychologists needed to have a "thorough appreciation of the methods and results of modern psychology". Once again, the point

while according to the method of uniform reduction, all animals share the same faculties, but these are more highly developed in humans. Of the three "methods", the method of variation was the one most consistent with the "principles of evolution" and "the least anthropomorphic, and therefore the most difficult" to apply in practice.

${ }^{30}$ Crucially, Morgan's point wasn't just about diversity in the level of mental faculties possessed-i.e., the extent to which a species relied on instinct versus intelligence or reason-but also diversity in the form that similar mental faculties could take in species adapted to different environmental niches. Morgan was one of the first animal scientists to take seriously the idea that the differing sensory capacities and demands of species was important to understanding the nature and structure of their minds. We thank a reviewer for emphasizing this to us. 
was that researchers needed to be aware of different possible ways to explain a given animal's behaviour. This provided key motivation for the Canon: that one should not leap to "higher" explanations of behaviour - e.g., in terms of the operation of reason-when "lower" explanations in terms of reflex, instinct, or intelligence were available. Crucially, it was not enough to defend higher explanations just on grounds of their putative "simplicity":

Is it not simpler to explain the higher activities of animals as the direct outcome of reason or intellectual thought, than to explain them as the complex results of mere intelligence or practical sense experience? Undoubtedly, it may in many cases seem simpler. It is the apparent simplicity of the explanation that leads many people to naively adopt it. But surely the simplicity of an explanation is no necessary criterion of its truth. (1894c, p54-55).

As well as rejecting simplicity as legitimate criterion for deciding between rival explanations, Morgan also thought that a general preference for attributing higher psychological capacities to animals (be it on grounds of "simplicity" or otherwise) ran against a proper understanding of evolution. Thus, a few pages later, in his discussion of the "method of variation", mentioned earlier, Morgan came back to the Canon:

[I]t is clear that any animal may be at a stage where certain higher faculties have not yet been evolved from their lower precursors; and hence we are logically bound not to assume the existence of these higher faculties until good reasons shall have been shown for such existence. In other words, we are bound to accept the principle above enunciated: that in no case is an animal activity to be interpreted as the outcome of the exercise of a higher psychical faculty, if it can be fairly interpreted as the outcome of the exercise of one which stands lower in the psychological scale." (1894c, p59).

Here we see Morgan connecting the Canon with the claim that higher faculties must evolve out of lower ones, and that for any species the higher faculties may not have developed. Hence, higher faculties could not just be assumed, and we needed to take extra care to rule out lower explanations. This was, in Morgan's words, the "logical basis" for the Canon.

The above passage raises an important interpretive issue that has received very little attention in previous discussions of Morgan's work: there is a crucial ambiguity in 
how Morgan stated and applied the Canon. When Morgan says that we shouldn't interpret behaviour as the product of a higher faculty when explanations in terms of lower faculties are available, are we meant to actively endorse the lower explanation over the higher one, or are we merely to withhold judgement-i.e., not "assume" the existence of the higher faculty - until additional evidence helps us to decide? In other words, is the Canon meant to be just a cautionary methodological principle that merely urges us not to endorse higher explanations too quickly, or is it meant to be something more like a decision principle that helps us to decide between rival higher and lower explanations when the behavioural evidence by itself fails to decide between them, and which actively favours lower explanations? Morgan has almost universally been interpreted as proposing the latter, and this is how the Canon is generally presented when it is invoked by modern comparative psychologists (see Fitzpatrick, 2008). However, in later chapters, Morgan himself actually seemed equivocate on how strong the Canon was meant to besometimes applying it merely to claim that a higher explanation is unsupported, and sometimes using it to explicitly defend the lower explanation. Compare, for instance, the first two passages below, which have more of a merely cautionary ring to them when it comes to endorsing the higher explanation, with the third, which actively endorses the lower explanation:

In accordance with our canon of interpretation, therefore, we are bound to assume no more without further warrant. (1894, p248, emphasis added).

[I]f the facts, supposing them to be biologically well founded, can be explained on the hypothesis of sense-experience, the greater appetence prevailing, we are bound by our canon of interpretation not to assume the higher faculty of perception. (1894, p370, emphasis added)

The question is: Can we or can we not explain the dog's action as the outcome of sense-experience, as indicative of intelligence profiting by association? I do not see how this can be denied. ...And if so, the canon of interpretation, so often referred to, makes it imperative for us who adopt it to accept the interpretation of the action as due to the simpler exercise of intelligence based on sense-experience rather than that according to which the dog perceived the relation between the chord and its arc. (1894, p302) 
Despite this seeming equivocation, Morgan clearly did use the Canon to advocate lower explanations, and generally expressed preferences for lower explanations when he saw them as able to explain the evidence. The motivation for this seemed to stem from the view of mental evolution discussed above: given that higher faculties must evolve out of lower ones, higher faculties must be rarer in nature than lower ones (for a modern critique of Morgan's reasoning, see Sober, 1998).

However, there is still, in our view, something wrong with viewing the Canon primarily as a preference for lower over higher, since this obscures what we see as the core message the Canon was meant to convey: the desperate need for the kind of experimental approach to studying animal behaviour he described in the preface and in more detail later on in the book. As we have seen, the primary concern of this third chapter was the proper application of the ejective method, which Morgan emphasized, required proper training in performing the "subjective induction"-i.e., a proper appreciation of the range of possible psychological processes that could lie behind particular behaviour - and a thorough understanding of the external aspects of the behaviour itself (the "objective induction"). What was wrong with those theorists that had leapt to higher accounts of animal behaviour too quickly was that they had "assume [d] this complexity of mental nature on grounds other than those of sound induction" and thus "depart[ed] from the methods of scientific procedure" (1894c, p55). Since Morgan now saw the careful experimental study of the development of behaviour - in the manner of Mann Jones and his own experiments - as the key way to settle questions about the nature of animal cognition, rather than seeing it fundamentally as a decision principle, and hence as a call to prefer lower explanations, the Canon should primarily be seen as a call for this new programme of investigation. ${ }^{31}$

\footnotetext{
31 As noted earlier, Radick $(2000,2007)$ traces the original motivation for the Canon, when Morgan first proposed it to the International Congress of Experimental Psychology in 1892 (Morgan, 1892a, p44), to his claims about the dependency of higher psychological capacities on language: "For Morgan, the canon was needed because animals, lacking language, probably lacked reason" (Radick, 2000, p4). However, Radick argues that around 1893 Morgan developed doubts about this denial of reason to animals, due to his hearing about the American naturalist R.L Garner's expedition to the Congo with the aim of providing phonographic proof of the existence of verbal language in apes. This led Morgan to re-frame the Canon in evolutionary terms in the Introduction. Whether or not Radick is correct about this change in rationale for the Canon, the principle should still be seen in the experimental context we have described.
} 


\section{Concluding remarks}

We have argued that Morgan underwent two quite different shifts of attitude toward the proper practice of comparative psychology. The first, which took place in the years leading up to the publication of Animal Life and Intelligence was a move away from his initial epistemic scepticism about the ejective method, towards a qualified acceptance of the Romanesian approach to comparative psychology. This was motivated by his evolving philosophy of science, which moved from a strict empiricism focused exclusively on observational verification, towards a more sophisticated empiricism that emphasized coherence ("congruity") as a test for truth in addition to direct observational verification. The second shift, which took place around 1891-3 was the realization that an experimental approach focused on development provided a much more promising route to getting at the true underlying nature of animal psychology than the largely theoretical, synthesizing, Romanesian approach. Though this move towards experimental methods was not entirely new, given his early experimental work on suicide in scorpions, and was very much in line with wider trends in contemporary biology, Morgan's correspondence with Mann Jones nonetheless played a vital stimulating and shaping role in this second shift in attitude, which ultimately led to Morgan's mature vision for comparative psychology. The mature Morgan fully accepted the Romanesian view that we needed to interpret animal behaviour ejectively, but he saw that this required a detailed understanding of the range of possible psychological processes that could account for a given behaviour, and that we understood the developmental trajectory of the behaviour in all of its aspects. Such a developmental-experimental approach could make the ejective method that much more powerful.

It is only in the context of this new approach that Morgan's famous Canon can be fully understood. In particular, the Canon shouldn't be viewed simply as a preference for lower over higher (though Morgan certainly did have such a preference), but rather as a refrain to those who would settle on accounts of animal psychology too quickly, and a call for more thorough experimental investigation of the genesis of animal behaviour.

\section{References}


Boakes, R. 1984. From Darwin to Behaviourism: Psychology and the Minds of Animals. Cambridge: Cambridge University Press.

Bradley, F.H. 1883. The Principles of Logic (2 ${ }^{\text {nd }}$ Edition). London: Oxford University Press.

Burkhart, R.W. 1999. Ethology, natural history, the life sciences, and the problem of place. Journal of the History of Biology, 32, 489-508.

Carus, P. 1891. The criterion of truth. The Monist, 1, 229-244.

Clifford, W.K. 1874. Body and mind. Fortnightly Review, December 1874, 714-736. Reprinted in L. Stephen and F. Pollock (eds.), Lectures and Essays by William Kingdon Clifford. London: Macmillan and Co. 1879.

Clifford, W.K. 1878. On the nature of things-in-themselves. Mind, 3, 57-67.

Costall, Allan. 1993. How Lloyd Morgan's Canon backfired. Journal of the History of the Behavioural Sciences, 29, 113-122.

Darwin, C. 1871/1981. The Descent of Man and Selection in Relation to Sex. Princeton, NJ: Princeton University Press.

Dewsbury, Donald A. 1984. Comparative Psychology in the Twentieth Century. Stroudsburg, PA: Hutchinson Ross.

Fitzpatrick, S. 2008. Doing away with Morgan's Canon. Mind \& Language, 23, 224- 246.

Goodrich, G. and C. Allen. 2007. Conditioned anti-anthropomorphism. Comparative Cognition \& Behaviour Reviews, 2, 147-150.

Gray, P.H. 1963. The descriptive study of imprinting in birds from 1873 to 1953. The Journal of General Psychology, 68, 333-346.

Huxley, T. H. 1874. On the hypothesis that animals are automata, and its history. Fortnightly Review, 95, 555-580.

James, W. 1879. Are we automata? Mind, 4, 1-22.

James, W. 1905. La notion de conscience. Archive de Psychologie, 5. Reprinted as "The notion of consciousness" in W. James, Essays in Radical Empiricism. New York: Dover. 2003.

Kimler, W. 2000. Reading Morgan's Canon: Reduction and unification in the forging of a science of the mind. American Zoologist, 40, 853-861.

Lubbock, J. 1877. The habits of ants. Fortnightly Review, 21, 287-306. 
Lubbock, J. 1882. Ants, Bees, and Wasps: A Record of Observations on the Habits of the Social Hymenoptera. London: Kegan Paul, Trench and Co.

Mach, E., 1886/1959. The Analysis of Sensations and the Relation of Physical to the Psychical. New York: Dover. 1959.

Mills, W. 1898. The Nature and Development of Animal Intelligence. New York: The MacMillan Company.

Morgan, C. Lloyd. 1882. Animal intelligence. Nature, 26, 523-524.

Morgan, C. Lloyd. 1883a. Note on the (alleged) suicide of the scorpion. Transactions of the South African Philosophical Society, 3, 19-23.

Morgan, C. Lloyd. 1883b. Suicide of scorpions. Nature, 27, 313-314.

Morgan, C. Lloyd. 1883c. Scorpion suicide. Nature, 27, 530.

Morgan, C. Lloyd. 1884a. Instinct. Nature, 29, 370-374.

Morgan, C. Lloyd. 1884b. Instinct. Nature, 29, 405.

Morgan, C. Lloyd. 1885. Springs of Conduct London: Kegan Paul, Trench and Co.

Morgan, C. Lloyd. 1886. On the study of animal intelligence. Mind, 11, 174-185.

Morgan, C. Lloyd. 1887. The generalisations of science. Mind, 12, 88-92

Morgan, C. Lloyd. 1890-1. Animal Life and Intelligence. London: Edward Arnold.

Morgan, C. Lloyd. 1892a. The limits of animal intelligence. International Congress of Experimental Psychology, Second Session, London, 1892, 44-48.

Morgan, C. Lloyd. 1892b. Experimental biology. Nature, 47, 25-26.

Morgan, C. Lloyd. 1892c. The limits of animal intelligence. Nature, 46, 417.

Morgan, C. Lloyd. 1892d. The law of psycho-genesis. Mind (New Series), 1, 72-93.

Morgan, C. Lloyd. 1893. The limits of animal intelligence. Fortnightly Review, 54, 223239.

Morgan, C. Lloyd. 1894a. Instinct and intelligence in chicks and ducklings. Natural Science, IV (25), 207-213.

Morgan, C. Lloyd. 1894b. The scope of psycho-physiology. Nature, 49, 504-505.

Morgan, C. Lloyd. 1894c. An Introduction to Comparative Psychology. London: Walter Scott.

Morgan, C. Lloyd. 1898. Review of Animal Intelligence: An Experimental Study. Nature, $51,249-250$. 
Morgan, C. Lloyd. 1899. Psychology and the ego. The Monist, 10, 62-84.

Morgan, C. Lloyd. 1903. An Introduction to Comparative Psychology (2nd Edition). London: Walter Scott.

Morgan, C. Lloyd. 1930. Autobiography of C. Lloyd Morgan. In C. Murchison (ed.), History of Psychology in Autobiography. New York: Cornell University Press.

Radick, G. 2000. Morgan's Canon, Garner's phonograph, and the evolutionary origins of language and reason. British Journal of History of Science, 33, 3-23.

Radick, G. 2007. The Simian Tongue. Chicago: Chicago University Press.

Reeks, M. 1920. Register of the Associates and Old Students of the Royal School of Mines and History of the Royal School of Mines. London: Royal School of Mines Old Students' Association.

Richards, R.J. 1987. Darwin and the Emergence of Evolutionary Theories of Mind and Behaviour. Chicago: Chicago University Press.

Romanes, G.J. 1880. Physiology of the Fresh Water Medusa. Science, 1, 64-65.

Romanes, G.J. 1882a. Animal Intelligence. London: Kegan Paul, Trench and Co.

Romanes, G.J. 1882b. The fallacy of materialism. Nineteenth Century, December 1882.

Romanes, G.J. 1883a. Mental Evolution in Animals. London: Kegan Paul, Trench and Co.

Romanes, G.J. 1883b. Observations on the physiology of Echinodermata. Journal of the Linnean Society of London, Zoology, 17, 131-137.

Romanes, G.J. 1884. Instinct. Nature, 29, 477.

Romanes. G.J. 1888. Mental Evolution in Man. London: Kegan Paul, Trench and Co.

Romanes, G.J. 1891. Animal Life and Intelligence by C. Lloyd Morgan. Mind, 16, 262267.

Romanes, G.J. 1896. Mind, Motion and Monism. London: Longmans, Green and Co.

Sober, E. 1998. Morgan's Canon. In C. Allen and D. Cummins (eds.), The Evolution of Mind. Oxford: Oxford University Press.

Spalding, D. 1873. Instinct: with original observations on young animals. Macmillan's Magazine, 27, 282-293.

Spencer, H. 1855. The Principles of Psychology. London: Longman, Brown, Green.

Spencer, H. 1870-2. The Principles of Psychology (Second Edition, Vols. 1-2). London: Williams and Norgate. 
Spencer, H. 1892. Justice. New York: D. Appleton and Co.

Thomas, R.K. 1998. Lloyd Morgan's Canon. In G. Greenberg and M. Haraway (eds.), Comparative Psychology: A Handbook. New York: Garland Press.

Thorndike, E. 1898. Animal intelligence: An experimental study of the associative processes in animals. Psychological Review Monograph Supplements, 2, i-109.

Whewell, W. 1858. Novum Organon Renovatum. London: John W. Parker.

Wilson, A. 2002. Experimental animal behaviour studies: The loss of initiative in Britain 100 years ago. History of Science, 40, 291-320.

Wozniak, R.H. 1993. Conwy Lloyd Morgan, mental evolution, and the Introduction to Comparative Psychology: An introduction. In R.H. Woznik (ed.) An Introduction to Comparative Psychology by C. Lloyd Morgan. London: Routledge. 